\title{
Prevalence and factors associated with overweight and obesity in French primary-school children
}

\author{
Hélène Thibault ${ }^{1,2, *}$, Caroline Carriere ${ }^{1,2}$, Coralie Langevin ${ }^{1,2}$, Edouard Kossi Déti ${ }^{1}$, \\ Pascale Barberger-Gateau ${ }^{2}$ and Sylvie Maurice ${ }^{1}$ \\ 'Univ. Bordeaux, ISPED, Centre INSERM U897-Epidemiologie-Biostatistique, F-33000 Bordeaux, France: \\ ${ }^{2}$ INSERM, ISPED, Centre INSERM U897-Epidemiologie-Biostatistique, Bordeaux, France
}

Submitted 13 January 2012: Final revision received 20 April 2012: Accepted 23 May 2012: First published online 7 September 2012

\begin{abstract}
Objective: To determine the prevalence of, and identify associated factors with, overweight and obesity in two samples of French children.

Design: We conducted two cross-sectional studies among two samples of children. Weight status, eating behaviour, sedentary activity, physical activity and parents' socio-economic status (SES) were collected using questionnaires filled by doctors during school health check-ups. Overweight and obesity were defined according to the age- and sex-specific BMI cut-off points of the International Obesity Taskforce. Multivariate analysis (logistic regression) was used to identify independent factors associated with overweight including obesity and obesity alone.

Setting: Aquitaine region (south-west France).

Subjects: Analyses were conducted among children aged $5-7$ years ( $n$ 4048) and 7-11 years ( $n$ 3619).

Results: Overweight prevalence was $9 \cdot 5 \%$ including $2 \cdot 2 \%$ of obesity in $5-7$-yearold children and $15.6 \%$ including $2.9 \%$ of obesity in $7-11$-year-old children. In both samples, overweight and obesity prevalence were higher in children whose parents had low or medium SES $(P<0 \cdot 05)$. Factors associated significantly $(P<0.05)$ and independently with higher overweight or obesity prevalence were female gender, low or medium parental SES, never or sometimes having breakfast, never eating at the school canteen, never having a morning snack, never or sometimes having a light afternoon meal and having high sedentary activity. Conclusions: Our data confirm that low SES, absence of breakfast and high sedentary activity are associated with a higher risk of being overweight or obese, but also highlight original potential protective factors such as eating at the canteen and high meal frequency.
\end{abstract}

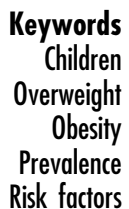

Since 1998, the WHO has recognized obesity as a major public health epidemic ${ }^{(1)}$. Indeed, overweight and obesity are established risk factors for several chronic diseases $^{(2-4)}$ and their prevalence in children has increased dramatically over the past few years worldwide, especially in the developed countries ${ }^{(5-7)}$. Several factors have been found to be associated with a higher risk of paediatric overweight and/or obesity, such as demographic, economic and social factors ${ }^{(8,9)}$, but also individual behaviours such as eating behaviour and physical or sedentary activity ${ }^{(10,11)}$. In France, the National Nutrition and Health Program ${ }^{(12)}$ was launched in 2001 by the Ministry of Health. One of its main objectives is to stop the increase in childhood obesity ${ }^{(12,13)}$. Thus, several studies on representative samples of French children have shown that, after increasing since the 1990s, overweight prevalence (including obesity) nationwide seems to have stabilized at about $16 \%$ since the $2000 s^{(14-17)}$.
Locally, various public health actions have been implemented such as in Aquitaine (south-west France) since November 2004 thanks to the programme 'Nutrition, Prevention and health of children and teenagers in Aquitaine' (www.nutritionenfantaquitaine.fr). Its objectives are to improve the dietary behaviour of children and teenagers by promoting healthy food consumption (particularly fruit and vegetables) and physical activity, thereby contributing to stabilizing childhood overweight prevalence ${ }^{(18)}$. Before and after implementing these interventions, surveys were conducted to provide guidelines and baseline data in order to evaluate the programme's impact on children (diet, level of physical activity, overweight prevalence). The objective of the present study was to identify social, economic and lifestyle factors associated with overweight or obesity in primary-school children (5-11 years old) using two surveys conducted among 5-7- and 7-11-year-old children in Aquitaine from 2007 to 2009. 


\section{Methods}

\section{Design and participants}

Two cross-sectional surveys were conducted in representative samples obtained by a cluster sampling procedure in Aquitaine. Clusters were primary schools.

Schools were randomly selected by taking into account districts (five in Aquitaine), school zone category (low socio-economic (LSE) area or non-LSE area) and geographical area (urban or rural) as well as school size. The database of schools' characteristics used for this sampling procedure was provided by the regional education authority. About $20 \%$ of primary schools of the five districts of the region were selected, and they all agreed to participate. The schools selected for each survey could be different.

Two samples of children were studied:

1. '5-7-year-old sample', examined from September 2007 to June 2008, among 5-7-year-old children ( $\left.n_{\text {schools }} 194\right)$;

2. '7-11-year-old sample', examined from September 2008 to June 2009 , among 7-11-year-old children ( $\left.n_{\text {schools }} 192\right)$.

All children aged 5-7 years or 7-11 years from the selected schools seen by school doctors or nurses during the systematic school health check-up were included in the surveys. Prior consent for participation was obtained from the children's parents. Data transmitted for the analysis were anonymous.

\section{Measurements}

In France, a medical school service, including nurses and medical doctors, is responsible for monitoring the health of children when they attend school. Every school year, a systematic medical health examination is performed once for all 5-7-year-old schoolchildren by school doctors and for all 7-11-year-old schoolchildren by school doctors and nurses. During this systematic examination, school doctors or nurses screen health or behaviour problems, but also check the weight status of each child.

The weight status of children was defined from anthropometric data (weight and height) collected by school doctors or nurses. Weight and height were measured in the morning or the afternoon (fasting is not necessary), using a standardized procedure and devices for measurement, at each school health centre. Weight was measured in lightly dressed children, without shoes, with school health centre scales. Height was measured using a stadiometer with the child standing up with his/her weight being equally distributed on the two feet, head back and buttock on the vertical part of the height gauge.

Other data concerning information about sex, age, eating behaviour, sedentary and physical activity and parents' socio-economic status (SES) were collected by questionnaires (validated by partners of the Aquitaine programme) completed by parents for the 5-7-year-old sample and by the school nurses for the 7-11-year-old sample.

\section{Variables}

Weight status

BMI $\left(\mathrm{kg} / \mathrm{m}^{2}\right)$ was calculated as [weight $\left.(\mathrm{kg})\right] /[\text { height }(\mathrm{m})]^{2}$. Weight status (normal, overweight or obesity) was classified using the cut-offs of the International Obesity Taskforce ${ }^{(19)}$.

\section{Eating behaviour}

Collected information concerned breakfast intake eating habits at the school canteen (only available for 5-7-year-old children), light afternoon meal intake, nibbling (never, sometimes or always for each item) and morning snack intake (yes/no).

\section{Sedentary activity}

Sedentary activity was estimated by weekly 'screen viewing time'. This time was obtained by adding up time spent watching television, using a computer and playing video games per week. For the 5-7-year-old and the 7-11-year-old samples, the mean of weekly 'screen viewing time' was estimated. Then sedentary activity level was divided into two classes using the mean of each sample: sedentary activity level was considered as 'high' when the screen viewing time was higher than the mean and as 'low' when lower.

\section{Physical activity in leisure centres and sport clubs}

Collected information concerned participation in leisure centres (never, some Wednesdays or every Wednesday, i.e. day without school) and in sport clubs (yes/no).

\section{Parents' socio-economic status}

SES of the father and mother was assessed according to their professional occupation. Three work categories, used by the French Ministry of Education, were defined according to the definition of the National Institute for Statistics and Economic Studies ${ }^{(20)}$ : 'high' (managers, executives, independent professionals); 'medium' (craftsmen, tradesmen, shopkeepers, proprietary business owners, office workers, employees, farmers, land-holders); and 'low' (manual workers, retired, unemployed, etc.). The SES of the household was assessed by combining both parents' status: 'high' if at least one of the parents had a high status; 'medium' if at least one had a medium status and neither had a high status; and 'low' if both parents had a low status.

\section{Low socio-economic area schools (state-run schools only)}

In France, state-run schools are classified by the school administration as LSE (low SES) schools or non-LSE (non-low SES) schools, according to the socio-economic characteristics of the area where they are located ${ }^{(21,22)}$.

\section{Other variables}

The National Institute for Statistics and Economic Studies classifies geographical areas as urban when continuously 
comprising 2000 persons or more. All other areas are classified as rural.

\section{Statistical analysis}

Data entry was performed using the EpiData software and analysis using the SAS statistical software package version $9 \cdot 1 \cdot 3$. Differences between samples were assessed by the $\chi^{2}$ test or the Kruskal-Wallis test. A $P$ value $<0.05$ was considered statistically significant.

Univariate analyses examined the association of data of interest (eating behaviour, sedentary and physical activity, parental SES) with overweight (obesity included) or obesity alone as respective dependent variable, using the $\chi^{2}$ test to determine statistical significance. Variables found to be significant at the univariate stage at $P<0 \cdot 20$ were then entered into a logistic regression analysis (multivariate analysis) using the same dependent variables.
Sampling design was taken into account during statistical analysis using a generalized estimating equation (GEE) model (GENMOD procedure). The Hosmer-Lemeshow goodness-of-fit test was used to assess the ability of the logistic regression model to predict the response variable.

\section{Results}

\section{Study population}

For the 5-7-year-old sample, 4048 children were included and 3619 for the 7-11-year-old sample. The male:female ratio was respectively $1 \cdot 05$ and $1 \cdot 01$.

Demographic characteristics, SES, eating habits, sedentary and physical activity of both 5-7-year-old and 7-11-year-old samples are described in Table 1 . The mean time of sedentary activity was $9 \cdot 1 \mathrm{~h}$ weekly for the $5-7$-year-old sample and $2 \cdot 8$ h weekly for the $7-11$-year-old sample.

Table 1 Weight status and characteristics of children: cross-sectional surveys in primary schools in the Aquitaine region, France, 2007-2009

\begin{tabular}{|c|c|c|c|c|}
\hline \multirow[b]{2}{*}{ Variable } & \multicolumn{2}{|c|}{ 5-7-year-old sample } & \multicolumn{2}{|c|}{ 7-11-year-old sample } \\
\hline & $n$ & $\%$ & $n$ & $\%$ \\
\hline Child's weight status & 4048 & & 3619 & \\
\hline Normal weight & 3665 & $90 \cdot 5$ & 3054 & $84 \cdot 4$ \\
\hline Overweight & 293 & $7 \cdot 3$ & 460 & $12 \cdot 7$ \\
\hline Obesity & 90 & $2 \cdot 2$ & 105 & $2 \cdot 9$ \\
\hline Gender & 4048 & & 3619 & \\
\hline Male & 2080 & $51 \cdot 4$ & 1815 & $50 \cdot 2$ \\
\hline Female & 1968 & $48 \cdot 6$ & 1804 & $49 \cdot 8$ \\
\hline Geographical area & 4048 & & 3619 & \\
\hline Urban & 2932 & $72 \cdot 4$ & 2360 & $65 \cdot 2$ \\
\hline Rural & 1116 & $27 \cdot 6$ & 1259 & $34 \cdot 8$ \\
\hline Zone & 4048 & & 3619 & \\
\hline Non-LSE & 3614 & $89 \cdot 3$ & 3365 & $93 \cdot 0$ \\
\hline LSE & 434 & $10 \cdot 7$ & 254 & $7 \cdot 0$ \\
\hline Parent's SES & 3964 & & 3532 & \\
\hline High & 1715 & $43 \cdot 3$ & 1443 & $40 \cdot 9$ \\
\hline Medium & 1441 & $36 \cdot 3$ & 1488 & $42 \cdot 1$ \\
\hline Low & 808 & $20 \cdot 4$ & 601 & $17 \cdot 0$ \\
\hline Eating at the canteen & 3837 & & & \\
\hline Never & 475 & $12 \cdot 4$ & \multicolumn{2}{|c|}{ Not available } \\
\hline Sometimes & 906 & $23 \cdot 6$ & & \\
\hline Always & 2456 & $64 \cdot 0$ & & \\
\hline Breakfast & 3881 & & 3619 & \\
\hline Always & 3634 & $93 \cdot 6$ & 3510 & $97 \cdot 0$ \\
\hline Never or sometimes & 247 & $6 \cdot 4$ & 107 & $3 \cdot 0$ \\
\hline Morning snack & 3850 & & 3596 & \\
\hline No & 2349 & $61 \cdot 0$ & 2569 & $71 \cdot 4$ \\
\hline Yes & 1501 & $39 \cdot 0$ & 1027 & $28 \cdot 6$ \\
\hline Light afternoon meal & 3864 & & 3584 & \\
\hline Always & 3446 & $89 \cdot 2$ & 3313 & $92 \cdot 4$ \\
\hline Never or sometimes & 418 & $10 \cdot 8$ & 271 & $7 \cdot 6$ \\
\hline Nibbling & 3599 & & 3540 & \\
\hline Never or sometimes & 3210 & $89 \cdot 2$ & 2970 & $83 \cdot 9$ \\
\hline Often or always & 389 & $10 \cdot 8$ & 570 & $16 \cdot 1$ \\
\hline Sedentary activity & 3403 & & 3243 & \\
\hline Low & 1852 & $54 \cdot 4$ & 1879 & $57 \cdot 9$ \\
\hline High & 1551 & $45 \cdot 6$ & 1364 & $42 \cdot 1$ \\
\hline Leisure club & 3825 & & 3515 & \\
\hline Every Wednesday & 383 & $10 \cdot 0$ & 271 & $7 \cdot 7$ \\
\hline Never or some Wednesdays & 3442 & $90 \cdot 0$ & 3244 & $92 \cdot 3$ \\
\hline Sports club & 3834 & & 3614 & \\
\hline Yes & 1859 & $48 \cdot 5$ & 2585 & $71 \cdot 5$ \\
\hline No & 1975 & $51 \cdot 5$ & 1029 & $28 \cdot 5$ \\
\hline
\end{tabular}

LSE, low socio-economic; SES, socio-economic status. 


\section{Prevalence of overweight and obesity}

For the 5-7-year-old sample, overweight (including obesity) and obesity prevalences were respectively $9.5 \%$ and $2 \cdot 2 \%$. For the 7-11-year-old sample, overweight (including obesity) and obesity prevalences were respectively $15 \cdot 6 \%$ and $2 \cdot 9 \%$ (Table 1 ).

\section{Factors associated with overweight (including obesity)}

Univariate analysis

For children from the 5-7-year-old sample, factors significantly associated $(P<0.05)$ with higher risk of overweight (including obesity) were: female gender, low or medium SES of the household, absence or rare intake of breakfast or light afternoon meal and having a high level of sedentary activity (Table 2).

For children from the 7-11-year-old sample, factors significantly associated $(P<0 \cdot 05)$ with higher risk of overweight (including obesity) were: female gender, low or medium SES of the household, absence of a morning snack and having a high level of sedentary activity (Table 2).

\section{Multivariate analysis}

In addition to variables significantly associated with overweight (including obesity) in the univariate analysis $(P<0 \cdot 05)$, variables with $P<0 \cdot 20$ were included in the multivariate final model: LSE status and eating at the canteen for the 5-7-year-old sample; LSE status and geographical area for the 7-11-year-old sample. Only significant variables were presented in Table 3 .

Among children from the 5-7-year-old sample, variables significantly associated with a higher prevalence of overweight (including obesity) in the multivariate analysis were: female gender, low or medium SES of the household, absence or rare breakfast intake, absence or rare light afternoon meal intake and having a high sedentary

Table 2 Factors associated with overweight (including obesity) in children aged 5-7 years ( $n$ 4048) and 7-11 years ( $n$ 3619): cross-sectional survey in primary schools in the Aquitaine region, France, 2007-2009

\begin{tabular}{|c|c|c|c|c|c|c|}
\hline \multirow[b]{2}{*}{ Variable } & \multicolumn{3}{|c|}{ 5-7-year-old sample } & \multicolumn{3}{|c|}{ 7-11-year-old sample } \\
\hline & OR & $95 \% \mathrm{Cl}$ & $P$ & OR & $95 \% \mathrm{Cl}$ & $P$ \\
\hline \multicolumn{7}{|l|}{ Gender } \\
\hline Male (ref.) & & & & & & \\
\hline Female & $1 \cdot 6$ & $1 \cdot 3,2 \cdot 0$ & $<10^{-4}$ & $1 \cdot 3$ & $1 \cdot 1,1 \cdot 5$ & 0.01 \\
\hline \multicolumn{7}{|l|}{ Geographical area } \\
\hline Urban (ref.) & & & & & & \\
\hline Rural & $1 \cdot 1$ & $0 \cdot 8,1 \cdot 4$ & $0 \cdot 50$ & $1 \cdot 2$ & $0 \cdot 9,1 \cdot 4$ & $0 \cdot 15$ \\
\hline \multicolumn{7}{|l|}{ Zone } \\
\hline Non-LSE (ref.) & & & & & & \\
\hline LSE & $1 \cdot 3$ & $1 \cdot 0,1 \cdot 8$ & 0.08 & $1 \cdot 4$ & $1 \cdot 0,2 \cdot 1$ & 0.07 \\
\hline \multicolumn{7}{|l|}{ Parent's SES } \\
\hline High (ref.) & & & & & & \\
\hline Medium & 1.5 & $1 \cdot 1,1 \cdot 9$ & $<10^{-4}$ & $1 \cdot 8$ & $1 \cdot 4,2 \cdot 2$ & $<10^{-4}$ \\
\hline Low & $2 \cdot 2$ & $1 \cdot 6,2 \cdot 9$ & & $2 \cdot 0$ & $1 \cdot 5,2 \cdot 6$ & \\
\hline \multicolumn{7}{|l|}{ Eating at the canteen } \\
\hline Never (ref.) & & & & & Not available & \\
\hline Sometimes & $0 \cdot 8$ & $0 \cdot 6,1 \cdot 0$ & 0.09 & & & \\
\hline Always & 0.7 & $0.5,1 \cdot 0$ & & & & \\
\hline \multicolumn{7}{|l|}{ Breakfast } \\
\hline \multicolumn{7}{|l|}{ Always (ref.) } \\
\hline Never or sometimes & $2 \cdot 1$ & $1 \cdot 5,3 \cdot 0$ & $<10^{-4}$ & $1 \cdot 2$ & $0 \cdot 7,2 \cdot 0$ & 0.39 \\
\hline \multicolumn{7}{|l|}{ Morning snack } \\
\hline No (ref.) & & & & & & \\
\hline Yes & $1 \cdot 1$ & $0 \cdot 8,1 \cdot 4$ & 0.79 & $0 \cdot 8$ & $0.6,0.9$ & 0.01 \\
\hline \multicolumn{7}{|l|}{ Light afternoon meal } \\
\hline Always (ref.) & & & & & & \\
\hline Never or sometimes & $1 \cdot 4$ & $1 \cdot 0,1 \cdot 8$ & 0.03 & $1 \cdot 0$ & $0 \cdot 7,1 \cdot 5$ & 0.90 \\
\hline \multicolumn{7}{|l|}{ Nibbling } \\
\hline Never or sometimes (ref.) & & & & & & \\
\hline Often or always & $1 \cdot 0$ & $0.7,1.5$ & 0.84 & $1 \cdot 0$ & $0 \cdot 8,1 \cdot 3$ & 0.95 \\
\hline \multicolumn{7}{|l|}{ Sedentary activity } \\
\hline Low (ref.) & & & & & & \\
\hline High & 1.5 & $1 \cdot 2,1 \cdot 9$ & $6 \times 10^{-4}$ & $1 \cdot 3$ & $1 \cdot 1,1 \cdot 6$ & 0.01 \\
\hline \multicolumn{7}{|l|}{ Leisure club } \\
\hline Every Wednesday (ref.) & & & & & & \\
\hline Never or some Wednesdays & $1 \cdot 2$ & $0 \cdot 8,1 \cdot 6$ & 0.37 & $1 \cdot 2$ & $0 \cdot 9,1 \cdot 7$ & 0.30 \\
\hline \multicolumn{7}{|l|}{ Sports club } \\
\hline Yes (ref.) & & & & & & \\
\hline No & $1 \cdot 0$ & $0 \cdot 9,1 \cdot 3$ & 0.57 & $1 \cdot 0$ & $0 \cdot 8,1 \cdot 2$ & 0.89 \\
\hline
\end{tabular}

Univariate logistic regression analysis.

ref., referent category; LSE, low socio-economic; SES, socio-economic status. 
Table 3 Factors associated with overweight (including obesity) in children aged $5-7$ years $(n$ 3834) and $7-11$ years ( $n$ 3448): cross-sectional survey in primary schools in the Aquitaine region, France, 2007-2009

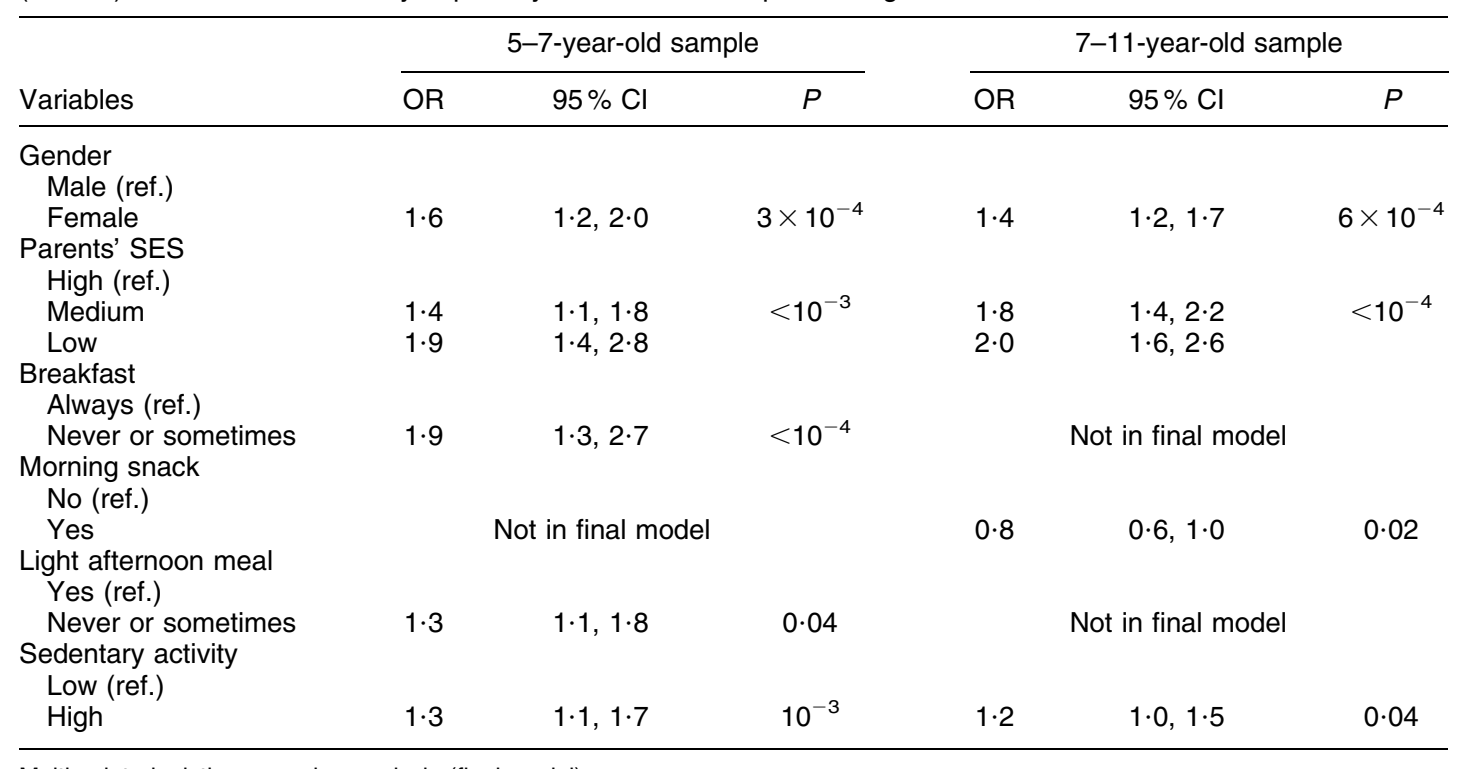

Multivariate logistic regression analysis (final model)

ref., referent category; SES, socio-economic status.

activity (all $P<0 \cdot 05$; Table 3 ). The model was adequate for predicting overweight (including obesity) in the target population: $\chi_{(5 \mathrm{df})}^{2}=3 \cdot 7 ; \quad P=0.59$ (Hosmer-Lemeshow goodness-of-fit test).

Among children from the 7-11-year-old sample, variables independently associated with a higher prevalence of overweight (including obesity) were: female gender, a low or medium SES of parents, absence of morning snack intake and having a high sedentary activity (all $P<0 \cdot 05$; Table 3 ). The model was adequate for predicting overweight (including obesity) in the target population: $\chi_{(7 \mathrm{df})}^{2}=3 \cdot 3 ; \quad P=0.86 \quad$ (Hosmer-Lemeshow goodness-of-fit test).

\section{Factors associated with obesity}

Univariate analysis

For the 5-7-year-old sample, variables significantly associated $(P<0.05)$ with a higher prevalence of obesity were: living in an LSE zone, low or medium SES of the household, never eating at the canteen, absence or rare breakfast intake, absence or rare light afternoon meal intake and having a high level of sedentary activity (Table 4).

For the 7-11-year-old sample, variables significantly associated $(P<0 \cdot 05)$ with a higher prevalence of obesity were: female gender, low or medium SES of the household, absence or rare breakfast intake and absence of morning snack (Table 4).

\section{Multivariate analysis}

In addition to variables significantly associated with overweight in the univariate analysis $(P<0 \cdot 05)$, variables with $P<0.20$ were included in the multivariate final model: gender and geographical area for children from the 5-7-year-old sample; LSE zone, light afternoon meal and sedentary activity for the 7-11-year-old sample. Only significant variables were presented in Table 5 .

Among children from the 5-7-year-old sample, factors significantly associated with a higher risk of obesity in the final model were: low or medium SES of the household and never eating at the canteen (both $P<0 \cdot 05$; Table 5). The model was adequate: $\chi_{(5 \mathrm{df})}^{2}=0 \cdot 6 ; P=0.99$ (Hosmer-Lemeshow goodness-of-fit test).

Among children from the 7-11-year-old sample, factors independently associated with a higher risk of obesity were: female gender, low or medium SES of the household, absence or rare intake of breakfast and absence of morning snack (all $P<0 \cdot 05$; Table 5). The model was adequate: $\chi_{(7 \mathrm{df})}^{2}=3 \cdot 8 ; P=0 \cdot 81$ (Hosmer-Lemeshow goodness-of-fit test).

\section{Discussion}

The present study shows cross-sectional association of overweight and obesity with both environmental socioeconomic factors (parental SES, geographical area) and individual behaviour (eating habits, level of sedentary activity). These data reinforce previous findings but also show original associations, especially regarding the protective role of eating at the canteen and of small snacks between main meals.

In the Aquitaine region, the prevalences of overweight including obesity and obesity (respectively $9.5 \%$ and $2 \cdot 2 \%$ for $5-7$-year-old children and $15 \cdot 6 \%$ and $2 \cdot 9 \%$ for 7-11-year-old children) are slightly lower than reported in 
Table 4 Factors associated with obesity in children aged $5-7$ years $(n 4048)$ and $7-11$ years $(n 3619)$ : cross-sectional survey in primary schools in the Aquitaine region, France, 2007-2009

\begin{tabular}{|c|c|c|c|c|c|c|}
\hline \multirow[b]{2}{*}{ Variable } & \multicolumn{3}{|c|}{ 5-7-year-old sample } & \multicolumn{3}{|c|}{ 7-11-year-old sample } \\
\hline & OR & $95 \% \mathrm{Cl}$ & $P$ & OR & $95 \% \mathrm{Cl}$ & $P$ \\
\hline \multicolumn{7}{|l|}{ Gender } \\
\hline Female & $1 \cdot 3$ & $0 \cdot 9,2 \cdot 0$ & $0 \cdot 18$ & $1 \cdot 8$ & $1 \cdot 2,2 \cdot 7$ & 0.004 \\
\hline \multicolumn{7}{|l|}{$\begin{array}{l}\text { Geographical area } \\
\text { Urban (ref.) }\end{array}$} \\
\hline Rural & 0.5 & $0 \cdot 4,1 \cdot 1$ & $0 \cdot 11$ & $1 \cdot 0$ & $0 \cdot 7,1 \cdot 5$ & 0.92 \\
\hline \multicolumn{7}{|l|}{ Zone } \\
\hline $\begin{array}{l}\text { Non-LSE (ref.) } \\
\text { LSE }\end{array}$ & $2 \cdot 3$ & $1 \cdot 4,3 \cdot 8$ & $2 \times 10^{-3}$ & $1 \cdot 6$ & $0 \cdot 8,3 \cdot 0$ & $0 \cdot 16$ \\
\hline \multicolumn{7}{|l|}{$\begin{array}{l}\text { Parent's SES } \\
\text { High (ref.) }\end{array}$} \\
\hline Medium & 1.9 & $1 \cdot 1,3 \cdot 4$ & $<10^{-4}$ & $1 \cdot 6$ & $1 \cdot 0,2 \cdot 6$ & 0.02 \\
\hline Low & $3 \cdot 4$ & $2 \cdot 0,6 \cdot 0$ & & $2 \cdot 1$ & $1 \cdot 2,3 \cdot 6$ & \\
\hline \multicolumn{7}{|l|}{ Eating at the canteen } \\
\hline Never (ref.) & & & & & Not available & \\
\hline Sometimes & $0 \cdot 3$ & $0.2,0.6$ & $6 \times 10^{-4}$ & & & \\
\hline Always & $0 \cdot 4$ & $0 \cdot 2,0 \cdot 7$ & & & & \\
\hline \multicolumn{7}{|l|}{ Breakfast } \\
\hline $\begin{array}{l}\text { Never or sometimes } \\
\text { Morning snack }\end{array}$ & $2 \cdot 7$ & $1 \cdot 5,5 \cdot 0$ & $10^{-3}$ & $2 \cdot 8$ & $1 \cdot 3,6 \cdot 0$ & 0.006 \\
\hline \multicolumn{7}{|l|}{$\begin{array}{l}\text { Morning snack } \\
\text { No (ref.) }\end{array}$} \\
\hline Yes & $1 \cdot 2$ & $0 \cdot 8,0 \cdot 9$ & $0 \cdot 32$ & $0 \cdot 6$ & $0 \cdot 4,1 \cdot 0$ & 0.03 \\
\hline \multicolumn{7}{|l|}{$\begin{array}{l}\text { Light afternoon meal } \\
\text { Always (ref.) }\end{array}$} \\
\hline Never or sometimes & $2 \cdot 2$ & $1 \cdot 3,3 \cdot 8$ & $3 \times 10^{-3}$ & $1 \cdot 6$ & $0 \cdot 9,3 \cdot 0$ & $0 \cdot 13$ \\
\hline \multirow{2}{*}{\multicolumn{7}{|c|}{$\begin{array}{l}\text { Nibbling } \\
\text { Never or sometimes (ref.) }\end{array}$}} \\
\hline $\begin{array}{l}\text { Never or sometimes (ref.) } \\
\text { Often or always }\end{array}$ & & & & & & \\
\hline Often or always & $1 \cdot 2$ & $0 \cdot 6,2 \cdot 3$ & 0.65 & $1 \cdot 2$ & $0 \cdot 7,2 \cdot 0$ & 0.42 \\
\hline \multicolumn{7}{|l|}{ Sedentary activity } \\
\hline High & $1 \cdot 9$ & $1 \cdot 3,3 \cdot 0$ & $2 \times 10^{-3}$ & $1 \cdot 4$ & $0 \cdot 9,2 \cdot 1$ & 0.09 \\
\hline Leisure club & & & & & & \\
\hline Every Wednesday (ref.) & & & & & & \\
\hline Never or some Wednesdays & $1 \cdot 3$ & $0 \cdot 6,2 \cdot 9$ & 0.43 & $1 \cdot 1$ & $0 \cdot 5,2 \cdot 5$ & 0.75 \\
\hline \multicolumn{7}{|l|}{ Sports club } \\
\hline $\begin{array}{l}\text { Yes (ref.) } \\
\text { No }\end{array}$ & 00 & & 00 & & & \\
\hline No & $0 \cdot 8$ & $0.5,1 \cdot 2$ & 0.25 & $1 \cdot 3$ & $0 \cdot 8,1 \cdot 9$ & 0.21 \\
\hline
\end{tabular}

Univariate logistic regression analysis.

ref., referent category; LSE, low socio-economic; SES, socio-economic status.

other studies conducted in France for 5-7-year-old children in 2000 (14\%, including $3.6 \%$ of obese children $)^{(23)}$ and $7-9$ year-old children in $2007(15 \cdot 8 \%$, including $2 \cdot 8 \%$ of obese children $)^{(14,15)}$ and in Western Europe ${ }^{(6)}$. Concerning gender, significantly more girls than boys were overweight (including obesity) among all children in primary schools, as shown in several French studies ${ }^{(17,23,24)}$.

In both samples we found an association between overweight and obesity and low parental SES that has been widely described previously in the literature ${ }^{(25-28)}$. However, LSE zone was no longer associated with overweight and obesity in multivariate models, probably because of its high correlation with parental SES.

Concerning individual behaviours, in both samples, a high level of sedentary activity was associated with a higher risk of being overweight (including obesity), a finding previously reported elsewhere, since time spent watching television and playing video games was positively associated with childhood overweight in France and among teenagers in Aquitaine ${ }^{(27-29)}$. The absence of an association found for all children between overweight or obesity and physical activity practice (unlike previously reported $^{(30,31)}$ ) may be partly explained by our procedure of measurement of physical activity that was based on selfreported information and that did not take into account the intensity of physical activity.

Our study also highlights the potential importance of some dietary behaviours. Lack of breakfast intake was an associated factor of overweight (including obesity) among children from the 5-7-year-old sample and of obesity among children from the 7-11-year-old sample. Indeed, children having breakfast every day had a lower risk than children who never or sometimes had breakfast. There is growing evidence of the association between regular breakfast consumption and health: breakfast intake may reduce the risk of chronic diseases due to its 
Table 5 Factors associated with obesity in children aged $5-7$ years $(n 3783)$ and $7-11$ years $(n 3510)$ : cross-sectional survey in primary schools in the Aquitaine region, France, 2007-2009

\begin{tabular}{|c|c|c|c|c|c|c|}
\hline \multirow[b]{2}{*}{ Variable } & \multicolumn{3}{|c|}{ 5-7-year-old sample } & \multicolumn{3}{|c|}{ 7-11-year-old sample } \\
\hline & OR & $95 \% \mathrm{Cl}$ & $P$ & OR & $95 \% \mathrm{Cl}$ & $P$ \\
\hline \multicolumn{7}{|l|}{ Gender } \\
\hline Female & \multicolumn{3}{|c|}{ Not in final model } & 1.9 & $1 \cdot 3,2 \cdot 8$ & $10^{-3}$ \\
\hline \multicolumn{7}{|l|}{ Parents' SES } \\
\hline Medium & $2 \cdot 0$ & $1 \cdot 1,3 \cdot 8$ & $<10^{-4}$ & $1 \cdot 6$ & $1 \cdot 0,2 \cdot 5$ & 0.03 \\
\hline Low & $3 \cdot 1$ & $1 \cdot 6,6 \cdot 0$ & & $2 \cdot 0$ & $1 \cdot 2,3 \cdot 5$ & \\
\hline \multicolumn{7}{|l|}{ Eating at the canteen } \\
\hline \multicolumn{7}{|l|}{ Never (ref.) } \\
\hline Sometimes & 0.4 & $0 \cdot 2,0 \cdot 7$ & $<10^{-4}$ & & Not in final model & \\
\hline Always & 0.5 & $0 \cdot 3,0 \cdot 8$ & & & & \\
\hline \multicolumn{7}{|l|}{ Breakfast } \\
\hline \multicolumn{7}{|l|}{ Always (ref.) } \\
\hline Never or sometimes & & Not in final model & & $2 \cdot 6$ & $1 \cdot 1,5 \cdot 9$ & 0.02 \\
\hline \multicolumn{7}{|l|}{ Morning snack } \\
\hline \multicolumn{7}{|l|}{ No (ref.) } \\
\hline Yes & & Not in final model & & 0.5 & $0.3,0.9$ & $0 \cdot 01$ \\
\hline
\end{tabular}

Multivariate logistic regression analysis (final model).

ref., referent category; SES, socio-economic status.

potential impact on the composition of overall diet ${ }^{(32,33)}$ and also reduce the risk of becoming overweight ${ }^{(10,34,35)}$.

Children from our 5-7-year-old sample eating at the canteen every day had a significantly lower risk of being obese than those who never ate at the canteen (data not available for the 7-11-year-old sample). This association between the risk of becoming obese and eating at the canteen has not previously been reported, although several studies confirm the relevance of the school canteen as a means of influencing children's eating habits ${ }^{(36)}$. Moreover, the link between eating at the canteen and SES, already found in several studies ${ }^{(36)}$, does not explain our results, since the association between obesity and canteen remains after adjustment on the other variables such as SES. Moreover, there was no interaction between eating at the canteen and SES $(P=0.58)$, indicating that the protective association was observed whatever the parental socio-economic level. In France, improving the nutritional quality of meals served in school catering tends to be a priority for public health authorities ${ }^{(37)}$ : nutritional recommendations (dealing with quantities and frequencies of food presentation) have been published according to the French National Nutrition and Health Program and many actions have been implemented to incite and help school catering staff to follow them.

Moreover, another original finding of our study is that children from the 5-7-year-old sample who never or rarely had a light afternoon meal after leaving school (usually around 16.00 hours, which is customary for schoolchildren in France) had a significantly higher risk of becoming overweight. The protective effect of the afternoon meal has been described previously and may be explained by a better distribution of energy intake, thus avoiding nibbling between lunch and dinner ${ }^{(38)}$, but no other study showed an independent association between afternoon meal and overweight, to our knowledge.

The current study also shows an association in children between the absence of morning snack intake and a higher risk of being overweight or obese. This may seem surprising because several studies report that morning snacks are often fatty and sweet and have a negative impact on food balance ${ }^{(39)}$. However, this could be the consequence of intervention aiming at suppressing or improving the composition of mid-morning snacks, especially in overweight or obese children. In Aquitaine, thanks to the programme 'Nutrition, Prevention and health of children and teenagers', many actions have been taken in order to stop systematic morning snacks in primary schools (5-7-year-old children), to improve their composition (by promoting the consumption of fruit, for example) and to dissuade parents from giving their child a morning snack. These recommendations have been followed relatively well in the region ${ }^{(40)}$. Thus, parents of overweight or obese children may now be aware of nutritional recommendations and the negative effects of morning snacks and so they are less likely to give them to their children, whereas parents of slim children may not necessarily feel concerned by these recommendations and are more likely to continue to give their children a morning snack. Taken altogether, our results on dietary habits suggest that a high meal frequency is associated with a lower risk of overweight or obesity.

A limitation of the present cross-sectional study is that causality cannot be inferred from our results. Nevertheless, some environmental factors such as parental SES and geographical area are clearly risk factors and not consequences of overweight and obesity. Moreover, as no dietary survey was available, analyses could not be 
adjusted for total energy intake. Thus the apparently protective association with eating at the canteen and having more meals should be interpreted with caution, in the absence of detailed information on the content of these meals.

On the other hand, the main strength of the study is the large representative sample of schools selected for analysis and of the consistent data on two different age groups of the same region.

As widely described in the literature, our data confirm the importance of some environmental or individual risk factors for childhood overweight and obesity. In opposition to environmental factors such as SES or geographical area, sedentary level and eating behaviour are individual factors that can be improved thanks to educational actions. These findings reinforce the relevance of the implementation of public health programmes, such as the French National Nutrition and Health Program and that in Aquitaine. Moreover, these findings underline the importance of implementing interventions in primary schools to achieve consistent behavioural changes, as recommended by recent international ${ }^{(1,41)}$, national ${ }^{(12,42)}$ and regional policies.

\section{Acknowledgements}

Sources of funding: This work was supported by Regional Health Agency of Aquitaine (ARS Aquitaine), as part of the subvention allocated to the Aquitaine program for nutrition, prevention and health. Conflicts of interest: The authors declare that they have no conflict of interests. Authors' contributions: H.T. was responsible for the conception, design, interpretation of the data, writing and revised the manuscript. C.C. performed the analysis, contributed to interpretation of data, writing and revised the manuscript. C.L. contributed to writing and revised the manuscript. E.K.D. contributed to the analysis. P.B.-G. contributed to the interpretation and revised the manuscript. S.M. revised the manuscript. All authors have read and approved the final manuscript. Acknowledgements: The authors thank the school nurses and doctors who collected and recorded measurements during child health surveillance, and all partners from the Local Education Authority in Bordeaux involved in the programme 'Nutrition, Prevention and Health of children and teenagers in Aquitaine'.

\section{References}

1. World Health Organization (2006) Addressing the Socioeconomic Determinants of Healthy Eating Habits and Physical Activity Levels Among Adolescents. Geneva: WHO.

2. Flaherman V \& Rutherford GW (2006) A meta-analysis of the effect of high weight on asthma. Arch Dis Child $\mathbf{9 1}$, 334-339.

3. Bibbins-Domingo K, Coxson P, Pletcher MJ et al. (2007) Adolescent overweight and future adult coronary heart disease. $N$ Engl J Med 357, 2371-2379.
4. Taylor ED, Theim KR, Mirch MC et al. (2006) Orthopedic complications of overweight in children and adolescents. Pediatrics 117, 2167-2174.

5. Jolliffe D (2004) Extent of overweight among US children and adolescents from 1971 to 2000. Int J Obes Relat Metab Disord 28, 4-9.

6. Lobstein T \& Frelut ML (2003) Prevalence of overweight among children in Europe. Obes Rev 4, 195-200.

7. Wang Y, Monteiro C \& Popkin BM (2002) Trends of obesity and underweight in older children and adolescents in the United States, Brazil, China, and Russia. Am J Clin Nutr 75, 971-977.

8. Moschonis G, Tanagra S, Vandorou A et al. (2010) Social, economic and demographic correlates of overweight and obesity in primary-school children: preliminary data from the Healthy Growth Study. Public Health Nutr 13, 1693-1700.

9. Shrewsbury V \& Wardle J (2008) Socioeconomic status and adiposity in childhood: a systematic review of crosssectional studies 1990-2005. Obesity (Silver Spring) 16, 275-284.

10. Haug E, Rasmussen M, Samdal O et al. (2009) Overweight in school-aged children and its relationship with demographic and lifestyle factors: results from the WHO-Collaborative Health Behaviour in School-aged Children (HBSC) study. Int J Public Health 54, Suppl. 2, 167-179.

11. Lioret S, Touvier M, Lafay L et al. (2008) Dietary and physical activity patterns in French children are related to overweight and socioeconomic status. J Nutr 138, 101-107.

12. Hercberg S, Chat-Yung S \& Chauliac M (2008) The French National Nutrition and Health Program: 2001-2006-2010. Int J Public Health 53, 68-77.

13. Girardet JP, Bocquet A, Bresson JL et al. (2009) French national program for nutrition and health: effects on children's health. Arch Pediatr 16, 3-6.

14. Rolland-Cachera MF, Castetbon K, Arnault N et al. (2002) Body mass index in 7-9-y-old French children: frequency of obesity, overweight and thinness. Int J Obes Relat Metab Disord 26, 1610-1616.

15. Salanave B, Peneau S, Rolland-Cachera MF et al. (2009) Stabilization of overweight prevalence in French children between 2000 and 2007. Int J Pediatr Obes 4, 66-72.

16. Peneau S, Salanave B, Maillard-Teyssier L et al. (2009) Prevalence of overweight in 6- to 15-year-old children in central/western France from 1996 to 2006: trends toward stabilization. Int J Obes (Lond) 33, 401-407.

17. Institut de veille sanitaire (2006) National Nutrition and Health Survey (ENNS), 2006: Nutritional Situation in France in 2006 According to Objective Indicators and Guidelines of the National Nutrition and Health Program (PNNS). Paris: InVS.

18. Thibault H, Boulard S, Carriere C et al. (2009) Prevention of childhood overweight and obesity program of Aquitaine region, France. Arch Pediatr 16, 570-572.

19. Cole TJ, Bellizzi MC, Flegal KM et al. (2000) Establishing a standard definition for child overweight and obesity worldwide: international survey. Br Med J 320, 1240-1243.

20. Institut national de la statistique et des études économiques (2003) Classifications of Occupations and of Social and Occupational Categories of Salaried Employees. Paris: INSEE.

21. Ministère de l'Education nationale (1981) Priority zones and priority education programs. Bull Officiel spécial, no. $1,6-10$.

22. Ministère de l'Education nationale (1981) Primary and secondary educations: priority zones. Bull Officiel 27, 2077-2079.

23. Duport N, Castetbon K, Guignon G et al. (2003) Corpulence des enfants scolarisés en grande section de maternelle en France métropolitaine et départements d'outre-mer: variations régionales et disparités urbaines. BEH 18-19, 73-88. 
24. Agence Française de Sécurité Sanitaire des Aliments (2009) Etude Individuelle Nationale des Consommations Alimentaires 2 (INCA 2) (2006-2007). Maisons-Alfort: AFSSA

25. Agras WS, Hammer LD, McNicholas F et al. (2004) Risk factors for childhood overweight: a prospective study from birth to 9.5 years. $J$ Pediatr 145, 20-25.

26. Baird J, Fisher D, Lucas P et al. (2005) Being big or growing fast: systematic review of size and growth in infancy and later obesity. BMJ 331, 929.

27. Thibault H, Contrand B, Saubusse E et al. (2010) Risk factors for overweight and obesity in French adolescents: physical activity, sedentary behavior and parental characteristics. Nutrition 26, 192-200.

28. Tremblay MS, Leblanc AG, Kho ME et al. (2011) Systematic review of sedentary behaviour and health indicators in school-aged children and youth. Int J Behav Nutr Phys Act $\mathbf{8}, 98$.

29. Lioret S, Maire B, Volatier JL et al. (2007) Child overweight in France and its relationship with physical activity, sedentary behaviour and socioeconomic status. Eur J Clin Nutr 61, 509-516.

30. Janssen I, Katzmarzyk PT, Boyce WF et al. (2005) Comparison of overweight and obesity prevalence in school-aged youth from 34 countries and their relationships with physical activity and dietary patterns. Obes Rev 6, 123-132.

31. Trost SG, Kerr LM, Ward DS et al. (2001) Physical activity and determinants of physical activity in obese and nonobese children. Int J Obes Relat Metab Disord 25, 822-829.

32. Vereecken C, Dupuy M, Rasmussen M et al. (2009) Breakfast consumption and its socio-demographic and lifestyle correlates in schoolchildren in 41 countries participating in the HBSC study. Int J Public Health $\mathbf{5 4}$, Suppl. 2, 180-190.
33. Giovannini M, Agostoni C \& Shamir R (2010) Symposium overview: do we all eat breakfast and is it important? Crit Rev Food Sci Nutr 50, 97-99.

34. Rampersaud GC, Pereira MA, Girard BL et al. (2005) Breakfast habits, nutritional status, body weight, and academic performance in children and adolescents. $J$ Am Diet Assoc 105, 743-760.

35. Tin SP, Ho SY, Mak KH et al. (2011) Breakfast skipping and change in body mass index in young children. Int $J$ Obes (Lond) 35, 899-906.

36. Finch M, Sutherland R, Harrison M et al. (2006) Canteen purchasing practices of year 1-6 primary school children and association with SES and weight status. Aust $N Z J$ Public Health 30, 247-251.

37. Lafay L, Volatier JL \& Martin A (2002) School catering in the INCA study (2nd part: School meals: nutritional and food composition, and impact on nutritional intake of children). Cab Nutr Diet 37, 395-404.

38. Bellisle F, Rolland-Cachera MF, Deheeger M et al. (1988) Obesity and food intake in children: evidence for a role of metabolic and/or behavioral daily rhythms. Appetite 11, $111-118$.

39. Bocquet A, Bresson JL, Briend A et al. (2003) The morning snack at school is inadequate and unnecessary. Arch Pediatr 10, 945-947.

40. Thibault H, Carriere C, Langevin C et al. (2010) Morning snack offer in primary school: outlook and practices in Aquitaine, France, between 2004 and 2008. Arch Pediatr 17, 1516-1521.

41. World Health Organization (2003) Diet, Nutrition and the Prevention of Chronic Diseases. Geneva: WHO.

42. Girardet JP, Bocquet A, Bresson JL et al. (2009) Le programme national nutrition santé (PNNS): quels effets sur la santé des enfants? Arch Pediatr 16, 3-6. 